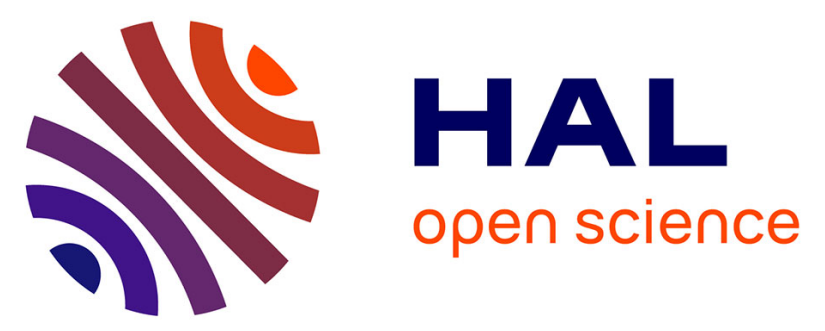

\title{
Very low-temperature epitaxial growth of Mn5Ge3 and Mn5Ge3C0.2 films on Ge(111) using molecular beam epitaxy
}

Matthieu Petit, Lisa Michez, Charles-Emmanuel Dutoit, Sylvain Bertaina, Voicu O Dolocan, Vasile Heresanu, Mathieu Stoffel, Vinh Le Thanh

\section{To cite this version:}

Matthieu Petit, Lisa Michez, Charles-Emmanuel Dutoit, Sylvain Bertaina, Voicu O Dolocan, et al.. Very low-temperature epitaxial growth of Mn5Ge3 and Mn5Ge3C0.2 films on Ge(111) using molecular beam epitaxy. Thin Solid Films, 2015, 589, pp.427-432. 10.1016/j.tsf.2015.05.068 . hal-01162158

\section{HAL Id: hal-01162158 \\ https://hal.science/hal-01162158}

Submitted on 15 Jun 2015

HAL is a multi-disciplinary open access archive for the deposit and dissemination of scientific research documents, whether they are published or not. The documents may come from teaching and research institutions in France or abroad, or from public or private research centers.
L'archive ouverte pluridisciplinaire $\mathbf{H A L}$, est destinée au dépôt et à la diffusion de documents scientifiques de niveau recherche, publiés ou non, émanant des établissements d'enseignement et de recherche français ou étrangers, des laboratoires publics ou privés. 


\title{
Very low-temperature epitaxial growth of $\mathrm{Mn}_{5} \mathrm{Ge}_{3}$ and $\mathrm{Mn}_{5} \mathrm{Ge}_{3} \mathrm{C}_{0.2}$ films on $\mathrm{Ge}(111)$ using molecular beam epitaxy
}

\author{
Matthieu Petit* \\ Aix-Marseille Université, CNRS, CINaM UMR 7325, 13288, Marseille, France. \\ Lisa Michez* \\ Aix-Marseille Université, CNRS, CINaM UMR 7325, 13288, Marseille, France. \\ Charles-Emmanuel Dutoit* \\ Aix-Marseille Université, CNRS, IM2NP UMR7334, 13397 cedex 20, Marseille, France. \\ Sylvain Bertaina* \\ Aix-Marseille Université, CNRS, IM2NP UMR7334, 13397 cedex 20, Marseille, France. \\ Voicu O. Dolocan* \\ Aix-Marseille Université, CNRS, IM2NP UMR7334, 13397 cedex 20, Marseille, France. \\ Vasile Heresanu* \\ Aix-Marseille Université, CNRS, CINaM UMR 7325, 13288, Marseille, France. \\ Mathieu Stoffel ${ }^{*}$ \\ Université de Lorraine, UMR CNRS 7198, Institut Jean Lamour, BP 70239, 54506 \\ Vanduvre-ls-Nancy, France \\ Vinh Le Thanh* \\ Aix-Marseille Université, CNRS, CINaM UMR 7325, 13288, Marseille, France.
}

\begin{abstract}
C-doped $\mathrm{Mn}_{5} \mathrm{Ge}_{3}$ compound is ferromagnetic at temperature up to $430 \mathrm{~K}$. Hence it is a potential spin injector into group-IV semiconductors. Segregation and diffusion of $\mathrm{Mn}$ at the $\mathrm{Mn}_{5} \mathrm{Ge}_{3} / \mathrm{Ge}$ interface could severely hinder the efficiency

\footnotetext{
* Corresponding author

Email address: matthieu.petit@univ-amu.fr (Matthieu Petit)
} 
of the spin injection. To avoid these two phenomena we investigate the growth of $\mathrm{Mn}_{5} \mathrm{Ge}_{3}$ and C-doped $\mathrm{Mn}_{5} \mathrm{Ge}_{3}$ films on $\mathrm{Ge}(111)$ substrates by molecular beam epitaxy at room-temperature. The reactive deposition epitaxy method is used to deposit these films. Reflection high energy electron diffraction, X-ray diffraction analysis, transmission electron microscopy and atomic force microscopy indicate that the crystalline quality is very high. Magnetic characterizations by superconducting quantum interference device and ferromagnetic resonance reinforce the structural analysis results on the thin films quality.

Keywords: Epitaxial growth, Low temperature, Reactive deposition epitaxy (RDE), Molecular Beam Epitaxy (MBE), $\mathrm{Mn}_{5} \mathrm{Ge}_{3}$, Ferromagnetic resonance (FMR)

PACS: 81.15.Hi, 81.05.Bx, 8.35.Ct, 61.05.cp, 68.37.Lp, 76.50.+g, 75.50.Cc

\section{Introduction}

During the last decade a great deal of effort has been devoted to the control of electron spins in semiconductor devices. Indeed semiconductor spintronics is believed to be a promising solution to develop beyond scaled metal5 oxide-semiconductor devices. These components would offer several advantages as nonvolatility, lower electric power consumption, increased data processing speed and integration densities [1. The realization of practical spintronic devices requires an efficient electrical injection of spin-polarized electrons from a ferromagnet into the conduction band of a semiconductor, a subsequent spinpolarized detection as well as an effective manipulation of spin in the semiconducting channel. Furthermore, the devices should be highly compatible with the already-existing silicon-based technology for easy technological implementation. A perfect control of the growth process of the materials layers and the interfaces between these layers will be required to manufacture efficient spintronic devices.

Among other suitable materials $\mathrm{Mn}_{5} \mathrm{Ge}_{3}$ presents all the prerequisite criteria necessary in spin devices: it is a well known ferromagnet with a magnetic ordering persisting up to the room temperature $\left(\mathrm{T}_{C}=297 \mathrm{~K}\right)[2$, with an ex- 
perimental spin polarization of $\mathrm{P}=15 \pm 5 \%[3$, and it has been demonstrated that $\mathrm{Mn}_{5} \mathrm{Ge}_{3}$ thin films could be grown epitaxially on a $\mathrm{Ge}(111)$ with the following orientation: $\mathrm{Mn}_{5} \mathrm{Ge}_{3}(001) / / \mathrm{Ge}(111)$ with [100] $\mathrm{Mn}_{5} \mathrm{Ge}_{3} / /[1-10] \mathrm{Ge}$, without the formation of any other phase [4, 5]. Moreover the value of the Curie temperature can be tuned in the range of $297-430 \mathrm{~K}$ by doping the $\mathrm{Mn}_{5} \mathrm{Ge}_{3}$ layers by a carbon concentration $\underline{\mathrm{C}_{x}}$ between $\underline{\mathrm{x}}=0$ and 0.7 . Such an enhancement has been explained due to $\mathrm{Mn}_{I I} \mathrm{Mn}_{I I}$ interactions mediated by carbon incorporated into interstitial sites of the $\mathrm{Mn}_{5} \mathrm{Ge}_{3}$ lattice 6. The crystalline structure and the epitaxial relationship between the $\mathrm{Mn}_{5} \mathrm{Ge}_{3} \mathrm{C}_{x}$ film and $\mathrm{Ge}(111)$ surface are not modified by the carbon doping. Usually the $\mathrm{Mn}_{5} \mathrm{Ge}_{3}$ and $\mathrm{Mn}_{5} \mathrm{Ge}_{3} \mathrm{C}_{x}$ films are grown by the so-called solid phase epitaxy (SPE) method which requires the co-deposition of Mn and C layers followed by annealing between $600 \mathrm{~K}$ and 920 30 $\mathrm{K}$ to activate the diffusion process.

Using the $\mathrm{Mn}_{5} \mathrm{Ge}_{3} \mathrm{C}_{x} / \mathrm{Ge}$ heterostructure in the spintronic devices will require the investigation of the spin-polarized injection into germanium from the $\mathrm{Mn}_{5} \mathrm{Ge}_{3} \mathrm{C}_{x}$. Even though very recently spin transport has been demonstrated in $\mathrm{Mn}_{5} \mathrm{Ge}_{3} / \mathrm{Ge} / \mathrm{Mn}_{5} \mathrm{Ge}_{3}$ nanowires [7, 8, spin transport in $\mathrm{Mn}_{5} \mathrm{Ge}_{3} / \mathrm{Ge} / \mathrm{Mn}_{5} \mathrm{Ge}_{3}$ thin films has to be studied. Because of the poor quality of germanium oxides, very few studies report their use as an efficient tunneling barrier [9]. This drawback leads to the spin injection into Ge directly from $\mathrm{Mn}_{5} \mathrm{Ge}_{3} \mathrm{C}_{x}$ thanks to the tunneling effect through a narrow width Schottky barrier. The electrical properties of the $\mathrm{Mn}_{5} \mathrm{Ge}_{3} \mathrm{C}_{x} / \mathrm{Ge}(111)$ Schottky contacts have been investigated 40 in previous works giving a Schottky barrier (SB) height between 0.30 and 0.56 $\mathrm{eV}$ [10, 11. The value of the SB width can be tuned in order to reduce Fermi level pinning at the interface by creating an ultrashallow and ultranarrow high doped layer at the vicinity of the $\mathrm{Mn}_{5} \mathrm{Ge}_{3} \mathrm{C}_{x} / \mathrm{Ge}(111)$ interface [12, 13. Thus the growth process of the $\mathrm{Mn}_{5} \mathrm{Ge}_{3} \mathrm{C}_{x}$ on the $\mathrm{Ge}(111)$ should preserve the ultra45 shallow layer. This might not be the case with the SPE method since it needs an annealing to form the $\mathrm{Mn}_{5} \mathrm{Ge}_{3} \mathrm{C}_{x}$ compound which can damage the high doped layer because of dopants and/or Mn diffusion [14.

In this article we propose a room temperature (RT) reactive deposition epi- 
taxy (RDE) method for the C-doped $\mathrm{Mn}_{5} \mathrm{Ge}_{3}$ deposition that allows to grow high crystalline quality films with abrupt interface on Ge(111). Low temperatures are indeed often used to reduce the segregation, diffusion, intermixing and island formation during growth processes of various materials like IV and III-V semiconductors or oxides [15, 16, 17, 18, 19, 20]. We have first focused on the early stage of the C-doped $\mathrm{Mn}_{5} \mathrm{Ge}_{3}$ thin films deposition by following in-situ the intensity of the patterns of the reflection high-energy electron diffraction (RHEED). We have then combined X-ray diffraction (XRD) and transmission electron microscopy (TEM) to assess the crystalline quality of the thin films. The crystallinity was eventually corroborated by magnetic characterizations such as superconducting quantum interference device (SQUID) and ferromagnetic resonance (FMR).

\section{Experimental details}

\subsection{Growth process and in-situ RHEED monitoring}

$\mathrm{Mn}_{5} \mathrm{Ge}_{3}$ and $\mathrm{Mn}_{5} \mathrm{Ge}_{3} \mathrm{C}_{0.2}$ thin films were grown by $\mathrm{MBE}$ (molecular beam epitaxy) on Ge(111) substrates by means of conventional Ge and Mn Knudsen effusion cells and a carbon sublimation source (SUKO) from MBE-Komponenten. The base pressure of the MBE chamber was $2.7 \times 10^{-8} \mathrm{~Pa}$. Prior to deposition of the thin films, the Ge substrates were chemically cleaned before introduction into the MBE chamber. Then the second part of the cleaning process consisted of an in-situ thermal outgassing at $720 \mathrm{~K}$ for several hours followed by flashed annealing up to $1020 \mathrm{~K}$ to remove the Ge surface oxide. After this process the Ge(111) surface was checked by RHEED with a beam acceleration voltage of $30 \mathrm{kV}$ and exhibits a quite well defined $\mathrm{c}(2 \times 4)$ reconstruction. A $15 \mathrm{~nm}$ thick Ge buffer layer was then deposited at a substrate temperature of $770 \mathrm{~K}$ followed by an annealing at $970 \mathrm{~K}$ during 10 minutes to insure a good starting surface prior to the growth of the $\mathrm{Mn}_{5} \mathrm{Ge}_{3}$ layers. These last steps were also monitored by in real time RHEED to control the quality of the Ge(111) surface. $\mathrm{Mn}_{5} \mathrm{Ge}_{3}$ and $\mathrm{Mn}_{5} \mathrm{Ge}_{3} \mathrm{C}_{0.2}$ thin films were formed by co-deposition of $\mathrm{Ge}, \mathrm{Mn}$ and $\mathrm{C}$ at room 
temperature on the Ge buffer layer. Cell fluxes were carefully calibrated using RHEED oscillations and a quartz microbalance to achieve the right stoichiometry of the layers. The growth was monitored in situ by RHEED, the formation of the $\mathrm{Mn}_{5} \mathrm{Ge}_{3}$ and $\mathrm{Mn}_{5} \mathrm{Ge}_{3} \mathrm{C}_{0.2}$ layers being confirmed by the observation of the $(\sqrt{3} \times \sqrt{3}) \mathrm{R} 30^{\circ}$ reconstruction characteristic of a $\mathrm{Mn}_{5} \mathrm{Ge}_{3}$ film [5, 21].

\subsection{Structural and topological characterizations}

X-ray diffraction data were collected using a Panalytical XPert PRO diffractometer with non-monochromatic $\mathrm{CuK}_{\alpha 1}$ radiation $(\lambda=1.541 \AA)$. Data were collected over a $2 \Theta$ range of $22-92^{\circ}$ with a step size of $0.004^{\circ}$. Transmission electron microscopy (TEM) investigations were performed at an accelerating voltage of $300 \mathrm{kV}$ on a JEOL JEM-3010 instrument with a spatial resolution of $1.7 \AA$. Cross-sections samples were prepared with a precision ion polishing system (PIPS). The topographies of the samples were imaged by atomic force microscopy (AFM) with a Nanoscope IIIA Multimode from Digital instruments on a $6 \times 6 \mu \mathrm{m}^{2}$ area.

\subsection{Magnetic properties}

The magnetic characterization of $\mathrm{Mn}_{5} \mathrm{Ge}_{3}$ and $\mathrm{Mn}_{5} \mathrm{Ge}_{3} \mathrm{C}_{0.2}$ have been performed using a SQUID magnetometer Quantum Design MPMSXL working up to $5 \mathrm{~T}$. Ferromagnetic resonance measurements were carried out on a conventional Bruker EMX spectrometer working at X band $(9.39 \mathrm{GHz})$. Samples of $2 \times 2 \mathrm{~mm}^{2}$ were glued on quartz suprazil rode and cooled from room temperature down to $80 \mathrm{~K}$. The static magnetic field was aligned perpendicular to the field. A modulation of the static field of 5 Oe at a frequency of $100 \mathrm{kHz}$ is used with a lock in amplifier to increase sensitivity and record the derivative of the FMR signal. 


\section{Results and discussion}

\subsection{Structural analysis}

sity of the RHEED pattern versus deposition time along the white line shown on fig 1 A). The inset on this figure give an example of this intensity profile along 


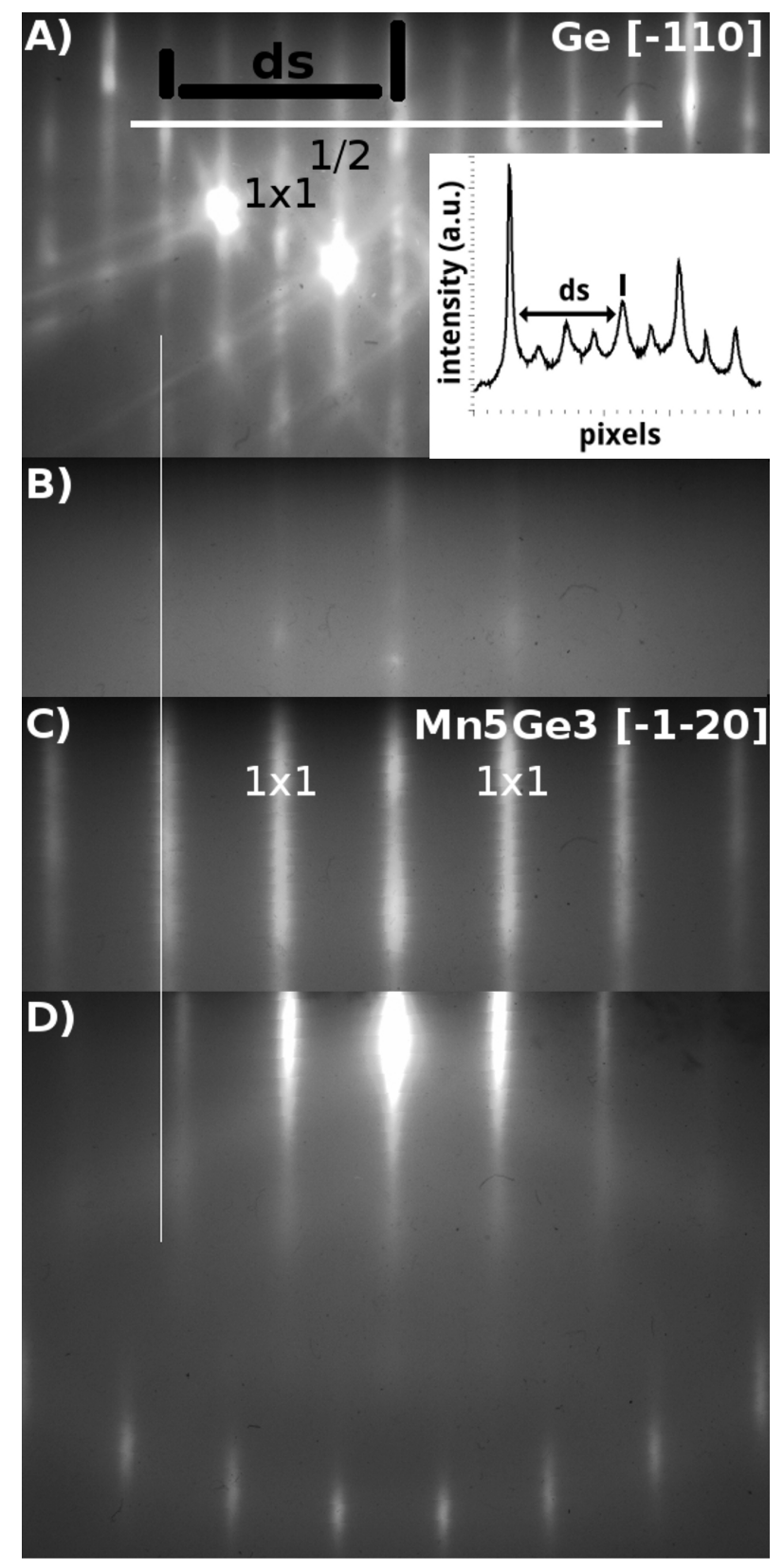

Figure 1: Characteristic RHEED patterns recorded during the growth of the $\mathrm{Mn}_{5} \mathrm{Ge}_{3} \mathrm{C}_{0.2}$ thin film. A) pattern of the Ge(111) surface (inset: intensity profile of the RHEED image along the white horizontal line), B) pattern below $2 \mathrm{~nm}$ thick, C) pattern at a thickness of 4 $\mathrm{nm}$ and D) pattern at the end of the growth corresponding to a thickness of $300 \mathrm{~nm}$. The white vertical line is a guide for the eyes positioned along the second $1 \times 1$ streak on the Ge[-110] azimuth of the Ge(111) surface. 


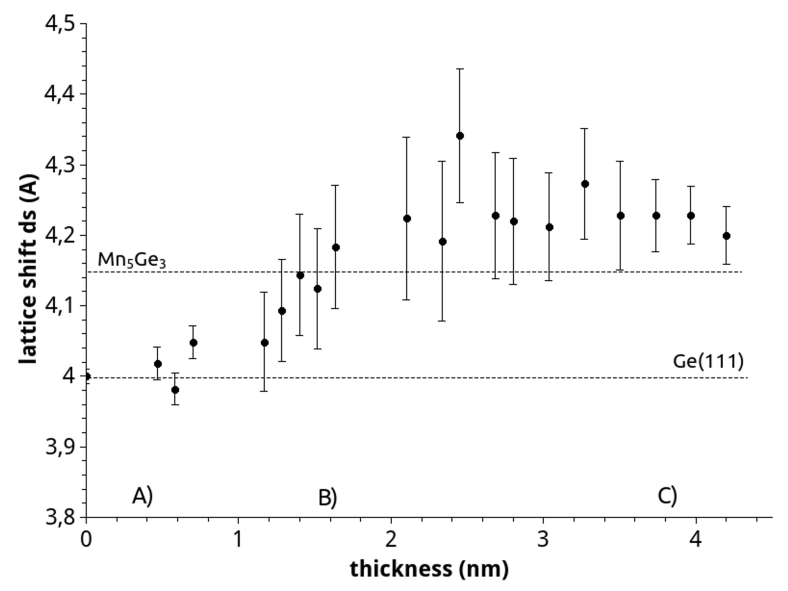

Figure 2: Evolution of the streak shift $d s$ defined on fig 1 A) versus the thickness of the deposition. Letters A), B), C) refer to the RHEED patterns of fig 1

this line in the case of the cleaned $\mathrm{Ge}(111)$ surface in the Ge[-110] azimuth. The length $d s$ defined also on fig, $1 \mathrm{~A})$ is measured between the specular and second $1 \times 1$ streaks. It was converted from pixels to angstroms using the streaks of Ge[-110] azimuth as length reference. The variation of $d s$ for the first $4 \mathrm{~nm}$ of the deposit is reported on fig, 2 .

The letters above the $\mathrm{x}$-axis correspond to the different diffraction images in fig 1 . The lattice length $d s$ evolves rather quickly from its value on a $\mathrm{Ge}(111)$ surface to the value of thick $\mathrm{Mn}_{5} \mathrm{Ge}_{3} \mathrm{C}_{0.2}$ (0001) oriented films. The error bars express the sharpness of the diffraction streaks used to calculate $d s$. We observe that the streaks remain blurry till $3 \mathrm{~nm}$ as the increase of the range of error bars proves it. It means that the C-doped $\mathrm{Mn}_{5} \mathrm{Ge}_{3}$ film is formed and relaxes on the $\mathrm{Ge}(111)$ surface over a transition layer of less than $3 \mathrm{~nm}$ thick. This value could be compared to the thickness of the ferromagnetic dead layer evaluated in our previous work (fig.2 in ref [23]) which was extrapolated to $1.7 \pm 0.3 \mathrm{~nm}$ but further analysis are required to determine the nature of this interfacial layer as well as its magnetic properties. The last value of $d s-4.19 \AA$ at a thickness of $4.2 \mathrm{~nm}$ - is very closed to the bulk lattice parameter of undoped $\mathrm{Mn}_{5} \mathrm{Ge}_{3}$ which 


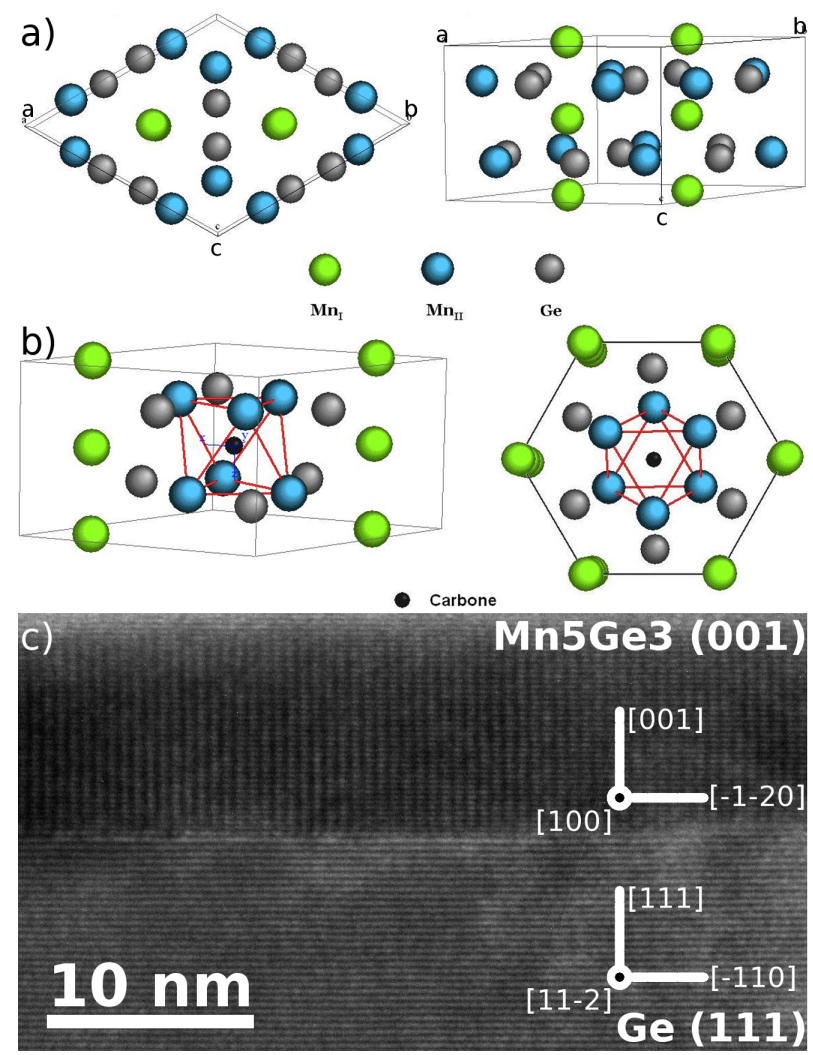

Figure 3: Colour online. a) $\mathrm{Mn}_{5} \mathrm{Ge}_{3}$ lattice with the two Mn sub-lattices in two different colors. b) carbon atom in the interstitial site of the $\mathrm{Mn}_{5} \mathrm{Ge}_{3}$ lattice formed by $\mathrm{Mn}_{I I}$ octahedron. c) TEM cross sectional image of a $\mathrm{Mn}_{5} \mathrm{Ge}_{3}$ thin film showing an atomic flat interface.

hand we measured the lattice shift from the digitalized profile of the RHEED intensity with an accuracy of hundredth angstrom even though the resolution of the aforesaid profile is limited by the size of pixels, on the other hand our value of $d s$ regards a $\mathrm{Mn}_{5} \mathrm{Ge}_{3} \mathrm{C}_{0.2}$ films: carbon atoms are introduced in the interstitial site of the $\mathrm{Mn}_{5} \mathrm{Ge}_{3}$ lattice which can induce an expansion of the in-plane lattice parameter (fig $3 \mathrm{a}$ ) and b)) [6].

The TEM picture displayed in fig $3 \mathrm{c}$ ) is a typical cross section of the $\mathrm{Mn}_{5} \mathrm{Ge}_{3}$ and $\mathrm{Mn}_{5} \mathrm{Ge}_{3} \mathrm{C}_{0.2}$ thin films grown on $\mathrm{Ge}(111)$ substrates. The interface is atomically sharp and the well resolved lattice planes extending throughout the whole 


$\begin{array}{lcccc} & \mathrm{Ge}[111] & \mathrm{Mn}_{5} \mathrm{Ge}_{3}[0002] & \mathrm{Mn}_{5} \mathrm{Ge}_{3}[0004] & \mathrm{Ge}[333] \\ \mathrm{Mn}_{5} \mathrm{Ge}_{3} & 0.04^{\circ} & 0.04^{\circ} & 0.10^{\circ} & 0.07^{\circ} \\ \mathrm{Mn}_{5} \mathrm{Ge}_{3} \mathrm{C}_{0.2} & 0.04^{\circ} & 0.21^{\circ} & 0.29^{\circ} & 0.07^{\circ}\end{array}$

Table 1: FWMH in degrees of the XRD $2 \Theta$ scans peaks of the $\mathrm{Ge}(111)$ substrate and $\mathrm{Mn}_{5} \mathrm{Ge}_{3}$ and $\mathrm{Mn}_{5} \mathrm{Ge}_{3} \mathrm{C}_{0.2}$ thin films

image reveal a high crystalline quality of the overgrown layer. We should mention that we did not observe threading dislocations even on TEM images of a larger scale although the lattice mismatch between the $\mathrm{Mn}_{5} \mathrm{Ge}_{3}$ and $\mathrm{Mn}_{5} \mathrm{Ge}_{3} \mathrm{C}_{0.2}$ layers and the $\mathrm{Ge}(111)$ substrates is $3.7 \%$. This was also the case for the SPE growth process [5].

The XRD $2 \Theta$ scan displayed in fig 4 a) was recorded on a $\mathrm{Mn}_{5} \mathrm{Ge}_{3}$ film with a thickness of $300 \mathrm{~nm}$. The scan presents the Ge[111], [222] and [333] peaks related to the $\mathrm{Ge}(111)$ substrate and only the (0002) and (0004) reflections of the $\mathrm{Mn}_{5} \mathrm{Ge}_{3}$ film corresponding to the bulk parameters. These peaks are doublets because of the $\mathrm{CuK}_{\alpha 1}$ and $\mathrm{CuK}_{\alpha 2}$ wavelengths, our XRD apparatus being not equipped with a monochromator. The other smaller peaks come from the $\mathrm{CuK}_{\beta}$ and the $\mathrm{CuK}_{\alpha 1} / 2$ radiations. We did not observe any other phase even if $\mathrm{Mn}_{5} \mathrm{Ge}_{3}$ is not the most thermodynamically stable one according to the Mn-Ge phase diagram [24] and different phases such as $\mathrm{Mn}_{11} \mathrm{Ge}_{8}, \mathrm{Mn}_{3} \mathrm{Ge}$, $\mathrm{Mn}_{5} \mathrm{Ge}_{2}$ have been obtained in the case of growth of $\mathrm{Mn}_{x} \mathrm{Ge}_{y}$ thin films on various substrates $[25,26$. Such a phenomenon was already noticed for the SPE method and was attributed to the epitaxial stabilization of the $\mathrm{Mn}_{5} \mathrm{Ge}_{3}$ phase on the Ge(111) substrate, both being of a threefold symmetry [5]. Fig 4 b) shows a zoom on the regions of the (0002) and (0004) reflections with a set of two peaks recording on the $\mathrm{Mn}_{5} \mathrm{Ge}_{3}$ film already presented in fig 4 a) and on a $\mathrm{Mn}_{5} \mathrm{Ge}_{3} \mathrm{C}_{0.2}$ film. Both films have a thickness of $300 \mathrm{~nm}$. The full width at half maximum (FWHM) of the different peaks resulting from the $\mathrm{CuK}_{\alpha 1}$ wavelength are summed-up in table 1.

From these values we observed that the crystallinity of the films is good which 

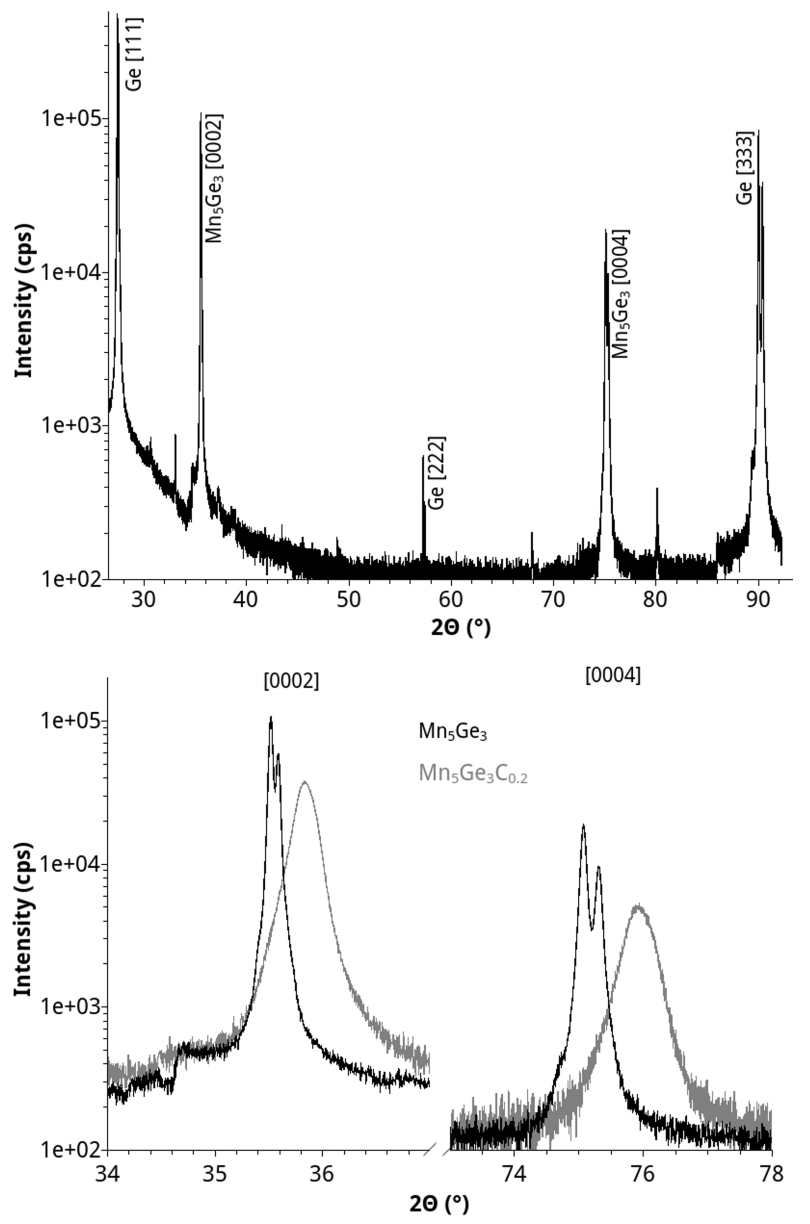

Figure 4: a) XRD $2 \Theta$ scan of a $300 \mathrm{~nm}$ thick film of $\mathrm{Mn}_{5} \mathrm{Ge}_{3}$. b) Zoom of XRD $2 \Theta$ scans of $\mathrm{Mn}_{5} \mathrm{Ge}_{3}$ and $\mathrm{Mn}_{5} \mathrm{Ge}_{3} \mathrm{C}_{0.2}$ thin films around the $\mathrm{Mn}_{5} \mathrm{Ge}_{3}$ [0002] and [0004] peak positions. 
confirms the RHEED and TEM results. However it seems that the addition of carbon affects the crystalline quality. Looking at the peaks position in fig $4 \mathrm{~b}$ ) and using Bragg's law, we calculated the lattice parameters along the c axis of both films. The estimated disparity is $0.046 \AA$ which means that there is 190 a compression shift of about $1 \%$ between the $\mathrm{Mn}_{5} \mathrm{Ge}_{3}$ and $\mathrm{Mn}_{5} \mathrm{Ge}_{3} \mathrm{C}_{0.2}$ films. This shift can be assigned to the variation of the lattice volume induced by the carbon atoms in the interstitial sites of the $\mathrm{Mn}_{5} \mathrm{Ge}_{3}$ lattice. The RHEED data (fig 2) have shown an in-plane expansion of the lattice which seems to be counterbalanced by this lattice shrinking along the $\mathrm{Mn}_{5} \mathrm{Ge}_{3}$ (0001) axis. In ref. [6], Slipukhina et al. calculated the increase of the $\mathrm{Mn}_{I I}-\mathrm{Mn}_{I I}$ atomic distance after introduction of carbon atoms in these interstitial sites and found a variation of $2.8 \%$. This theoritical value on the $\mathrm{Mn}_{I I}-\mathrm{Mn}_{I I}$ atomic distance is rather consistent with our results regarding the whole lattice alteration. To be complete Gajdzik et al. observed a lattice compression in each direction $(0.7 \%$ and $1.1 \%$ along the a and $\mathrm{c}$ axis respectively) caused by the incorporation of $\mathrm{C}$ in $\mathrm{Mn}_{5} \mathrm{Ge}_{3} \mathrm{C}_{x}$ thin films prepared by sputtering at $680 \mathrm{~K}$ 27]. The difference between these results and our observations is assumed to come from the growth processes.

\subsection{Magnetic characterizations}

Magnetization measurements have been performed on $\mathrm{Mn}_{5} \mathrm{Ge}_{3}$ and $\mathrm{Mn}_{5} \mathrm{Ge}_{3} \mathrm{C}_{0.2}$ films of $15 \mathrm{~nm}$ thickness. The saturation magnetization $\left(\mathrm{M}_{s}\right)$ has been estimated to be $1000 \mathrm{emu} / \mathrm{cm}^{3}$. These values are highly dependent on the knowledge of the thickness of the films. However we did not notice a significant variation of $\mathrm{M}_{s}$ with carbon concentration, which remains at $1000 \pm 100 \mathrm{emu} / \mathrm{cm}^{3}$ in the range of values generally observed in bulk [28] or layer [23] $\mathrm{Mn}_{5} \mathrm{Ge}_{3} \mathrm{C}_{x}$.

The temperature dependence of the saturation magnetization measured in an applied field of $\mathrm{H}=1.0 \mathrm{~T}$ for different carbon concentrations is presented in figure 5. In order to compare the influence of the RT-RDE method on the magnetic properties of the $\mathrm{Mn}_{5} \mathrm{Ge}_{3} \mathrm{C}_{x}$, we added $\mathrm{M}_{s}(T)$ curves measured on $\mathrm{Mn}_{5} \mathrm{Ge}_{3} \mathrm{C}_{x}$ samples grown by the SPE method 29] with various carbon concentrations: 
$\mathrm{x}=0,0.25$ and 0.6 . In the case of this method, the carbon concentration $\mathrm{C}=0.6$ gives the highest Curie temperature at $430 \mathrm{~K}$. Without carbon, no significant discrepancy is found. For low carbon concentrations, the shapes of the $\mathrm{M}_{s}(T)$ curves slightly differ since the curve of the SPE $\mathrm{x}=0.25$ sample has a rather broad tail towards the high temperatures. The Curie temperature is higher in the case of the RDE $\mathrm{x}=0.2$ sample $\left(\mathrm{T}_{c}=399 \mathrm{~K}\right)$ than in the case of the SPE $\underline{x}=0.25$ sample $\left(T_{c}=345 \mathrm{~K}\right)$. These observations are explained by the fact that the homogeneity of the distribution of carbon atoms is greatly enhanced by the RDE growth process compare to the SPE one leading to an improvement of the magnetic properties. To confirm this fact, the magnetizations of the $\mathrm{Mn}_{5} \mathrm{Ge}_{3}$ and $\mathrm{Mn}_{5} \mathrm{Ge}_{3} \mathrm{C}_{0.2}$ RDE samples are plotted versus the temperature normalized by the $\mathrm{T}_{c}$ of each sample $\left(\mathrm{T}_{c}\left(\mathrm{Mn}_{5} \mathrm{Ge}_{3}\right)=296 \mathrm{~K}, \mathrm{~T}_{c}\left(\mathrm{Mn}_{5} \mathrm{Ge}_{3} \mathrm{C}_{0.2}\right)=399 \mathrm{~K}\right)$ in the inset of fig.5. The curves are perfectly superimposed asserting the good homogeneity of the carbon distribution in the $\mathrm{Mn}_{5} \mathrm{Ge}_{3} \mathrm{C}_{0.2}$ film resulting from the $\mathrm{RDE}$ growth mode. It is known 27] that the ferromagnetic $\mathrm{Mn}_{I I}-\mathrm{Mn}_{I I}$ coupling is enhanced by hybridization through the carbon. A high homogeneity of carbon improves the efficiency of hybridization and increases $T_{c}$.

Ferromagnetic resonance (FMR) has been recorded on thin films of $\mathrm{Mn}_{5} \mathrm{Ge}_{3}$ 235 and $\mathrm{Mn}_{5} \mathrm{Ge}_{3} \mathrm{C}_{0.2}$. The FWHM is presented in figure 6. For the carbon free system $(x=0)$ at room temperature, the linewidth is large but quickly decreases when decreasing the temperature and reaches an almost constant value of about $7.5 \mathrm{mT}$ when $T<270 \mathrm{~K}$. This is due to the phase transition of $\mathrm{Mn}_{5} \mathrm{Ge}_{3}$ from the paramagnetic phase to the ferromagnetic one at RT. The fluctuation of the magnetization while crossing $T_{c}$ dramatically increase the linewidth. For $\mathrm{Mn}_{5} \mathrm{Ge}_{3} \mathrm{C}_{0.2}$, the Curie temperature is much higher with a value estimated at about $399 \mathrm{~K}$ and has no effect on the linewidth in the range of temperature we probed. FWHM is stable, decreasing from $3.5 \mathrm{mT}$ at room temperature down to $2.5 \mathrm{mT}$ at $100 \mathrm{~K}$.

245

The linewidth of the FMR uniform mode is directly related to the intrinsic quality of the sample. It reflects the intrinsic magnetic damping (homogeneous 


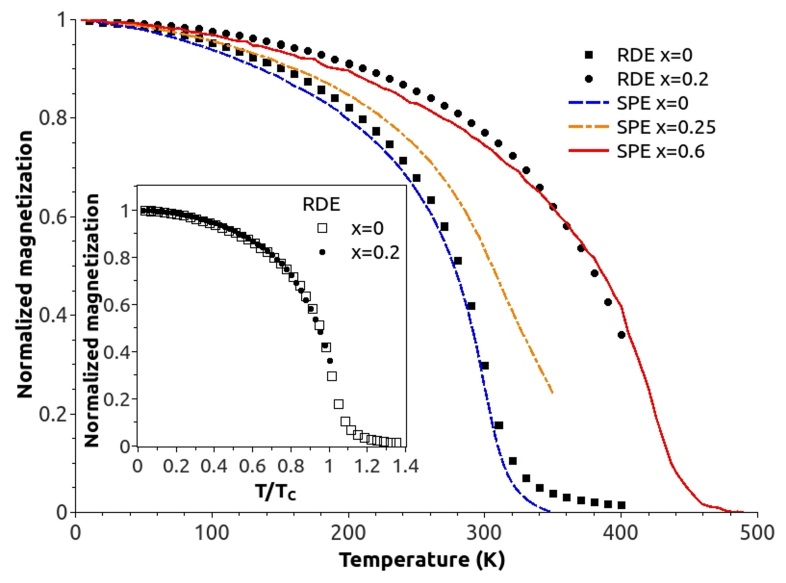

Figure 5: (colour online) Normalized magnetization versus temperature for $\mathrm{Mn}_{5} \mathrm{Ge}_{3}$ and $\mathrm{Mn}_{5} \mathrm{Ge}_{3} \mathrm{C}_{0.2}$ samples grown by RDE (applied field $\mathrm{H}=1.0 \mathrm{~T}$ ) and for $\mathrm{Mn}_{5} \mathrm{Ge}_{3} \mathrm{C}_{x}$ samples $\underline{(\mathrm{x}=0,0.25,0.6) \text { grown by SPE (data from fig.2 29]). Inset: Normalized magnetization versus }}$ $\mathrm{T} / \mathrm{T}_{c}$ for the RDE samples.

broadening) and the film inhomogeneities (inhomogeneous broadening) due to a wide variety of parameter variations (film thickness, surface anisotropy, applied field etc.). FMR of $\mathrm{Mn}_{5} \mathrm{Ge}_{3}$ has been studied in the past [30] showing a linewidth of many hundreds of $\mathrm{mT}$. The samples grown by SPE do not exhibit clear FMR signal. The sharpness of the FMR linewidth of $\mathrm{Mn}_{5} \mathrm{Ge}_{3}$ and $\mathrm{Mn}_{5} \mathrm{Ge}_{3} \mathrm{C}_{0.2}$ grown using the RDE method is a clear evidence of the high quality of the sample and the great improvement of the growing method.

\section{Conclusion}

We have demonstrated the reactive deposition epitaxy of $\mathrm{Mn}_{5} \mathrm{Ge}_{3} \mathrm{C}_{x}$ on $\mathrm{Ge}(111)$ substrates at room temperature. $\mathrm{Mn}_{5} \mathrm{Ge}_{3} \mathrm{C}_{x}$ thin films up to $300 \mathrm{~nm}$ thick were grown. Structural analysis were performed on these films using various characterization means. The crystallinity was proved to be of good quality with no threading dislocation. The interfaces between the $\mathrm{Ge}(111)$ substrates and the $\mathrm{Mn}_{5} \mathrm{Ge}_{3} \mathrm{C}_{x}$ films were atomically sharp and the films surfaces remained smooth during the growth process. Magnetization versus temperature measure- 


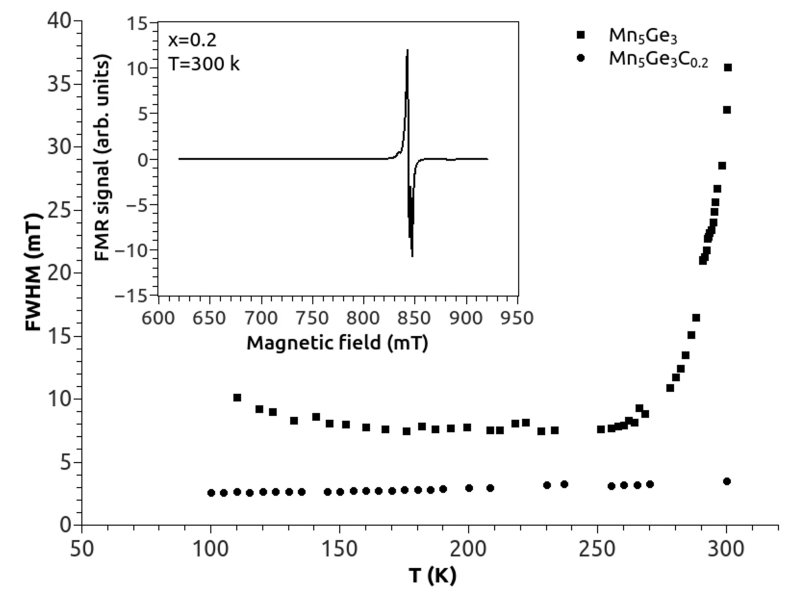

Figure 6: Temperature dependence of the FMR full width at half maximum of $\mathrm{Mn}_{5} \mathrm{Ge}_{3}$ and $\mathrm{Mn}_{5} \mathrm{Ge}_{3} \mathrm{C}_{0.2}$. The magnetic field is set perpendicular to the film and the microwave frequency was $9.4 \mathrm{GHz}$. The inset is an example of FMR signal of $\mathrm{Mn}_{5} \mathrm{Ge}_{3} \mathrm{C}_{0.2}$ recorded at $300 \mathrm{~K}$.

ments confirmed the values of the Curie temperature of being similar to those usually found for $\mathrm{Mn}_{5} \mathrm{Ge}_{3} \mathrm{C}_{x}$ thin films. Moreover very sharp FMR spectra with a FWHM below $7.5 \mathrm{mT}$ were recorded which is a very significant evidence of the high quality of the thin films grown by our RDE method.

\section{Acknowledgements}

The authors would like to thank Alain Ranguis for the AFM observations, Mohammad El Zrir, Damien Chaudanson and Serge Nitsche for the TEM preparation and pictures and Cyril Coudreau for the technical support regarding the MBE chambers. The authors thank the interdisciplinary French EPR network RENARD ( CNRS - FR3443). Parts of this work has been carried out thanks to the support of the A*MIDEX project (ANR-11-IDEX-0001-02) funded by the "Investissements d'Avenir" French Government program, managed by the French National Research Agency (ANR). 
[1] S. A. Wolf, D. D. Awschalom, R. A. Buhrman, J. M. Daughton, S. von

口 Molnár, M. L. Roukes, A. Y. Chtchelkanova, D. M. Treger, Spintronics: a spin-based electronics vision for the future. Science (New York, N.Y.)

п 294 (5546) (2001) 1488-95. doi:http://dx.doi.org/10.1126/science. 1065389

URL http://www.ncbi.nlm.nih.gov/pubmed/11711666

[2] Y. Tawara, K. Sato, On the magnetic anisotropy of single crystal of mn5ge3, Journal of the Physical Society of Japan 18 (6) (1963) 773-777. doi:http: //dx.doi.org/10.1143/JPSJ.18.773. ski, Spin-resolved photoemission of a ferromagnetic mn5ge3(0001) epilayer on ge(111), Journal of Applied Physics 105 (7) (2009) -. doi:http://dx.doi.org/10.1063/1.3103336. URL http://scitation.aip.org/content/aip/journal/jap/105/7/ $10.1063 / 1.3103336$

[4] C. Zeng, S. C. Erwin, L. C. Feldman, A. P. Li, R. Jin, Y. Song, J. R. Thompson, H. H. Weitering, Epitaxial ferromagnetic mn5ge3 on ge(111),

10 Applied Physics Letters 83 (24) (2003) 5002-5004. doi:http://dx.doi. org/10.1063/1.1633684. URL http://link . aip.org/link/?APL/83/5002/1

[5] S. F. Olive-Mendez, A. Spiesser, L. A. Michez, V. Le Thanh, A. Glachant, J. Derrien, T. Devillers, A. Barski, M. Jamet, Epitaxial growth of mn5ge3/ge(111) heterostructures for spin injection Thin Solid Films 517 (1) (2008) 191-196. doi:http: //dx.doi.org/10.1016/j.tsf.2008.08.090

a URL http://ww.sciencedirect.com/science/article/pii/ S0040609008009176 
[6] I. Slipukhina, E. Arras, P. Mavropoulos, P. Pochet, Simulation of the enhanced curie temperature in mn5ge3cx compounds, Applied Physics Letters 94 (19) (2009) 192505. doi:http://dx.doi.org/10.1063/1.3134482 URL http://link.aip.org/link/APPLAB/v94/i19/p192505/s1\&Agg= doihttp://link.aip.org/link/?APL/94/192505/1

[7] J. Tang, C.-Y. Wang, M.-H. Hung, X. Jiang, L.-T. Chang, L. He, P.-H. Liu, H.-J. Yang, H.-Y. Tuan, L.-J. Chen, K. L. Wang, Ferromagnetic germanide in ge nanowire transistors for spintronics application., ACS nano 6 (6) (2012) 5710-7. doi:http://dx.doi.org/10.1021/nn301956m. URL http://www.ncbi.nlm.nih.gov/pubmed/22658951

[8] J. Tang, C.-Y. Wang, L.-T. Chang, Y. Fan, T. Nie, M. Chan, W. Jiang, Y.-T. Chen, H.-J. Yang, H.-Y. Tuan, L.-J. Chen, K. L. Wang, Electrical spin injection and detection in mn5ge3/ge/mn5ge3 nanowire transistors. Nano letters 13 (9) (2013) 4036-43. doi:http://dx.doi.org/10.1021/ nl401238p.

URL http://www.ncbi.nlm.nih.gov/pubmed/23937588

[ [9] A. Spiesser, S. Watanabe, H. Saito, S. Yuasa, K. Ando, Effective creation of spin polarization in p-type ge from a fe/geo2 tunnel contact, Japanese Journal of Applied Physics 52 (4S) (2013) 04CM01. doi:http://dx.doi. org/10.7567/JJAP.52.04CM01. URL http://stacks . iop.org/1347-4065/52/i=4S/a=04CM01

[10] T. Nishimura, O. Nakatsuka, S. Akimoto, W. Takeuchi, S. Zaima, 325 - Crystalline orientation dependence of electrical properties of $\mathrm{mn}$ germanide/ge(111) and (001) schottky contacts, Microelectronic Engineering 88 (5) (2011) 605-609. doi:http://dx.doi.org/10.1016/j.mee.2010. 08.014

1] URL http://linkinghub.elsevier.com/retrieve/pii/ 330 S016793171000300X

[11] A. Sellai, A. Mesli, M. Petit, V. Le Thanh, D. Taylor, M. Henini, Barrier 
contacts for spin injection, Semiconductor Science and Technology 27 (3)

335

[12] G. Scappucci, G. Capellini, W. C. T. Lee, M. Y. Simmons, Ultradense phosphorus in germanium delta-doped layers, Applied Physics Letters

[13] G. Scappucci, G. Capellini, W. M. Klesse, M. Y. Simmons, Phosphorus atomic layer doping of germanium by the stacking of multiple $\delta$ layers., Nanotechnology 22 (37) (2011) 375203. doi:http://dx.doi.org/10.1088/ 0957-4484/22/37/375203.

URL http://www.ncbi.nlm.nih.gov/pubmed/21857100

[14] A. Spiesser, H. Saito, R. Jansen, S. Yuasa, K. Ando, Large spin accua mulation voltages in epitaxial mn5ge3 contacts on ge without an oxide 350 tunnel barrier Physical Review B 90 (20) (2014) 205213. doi:http: //dx.doi.org/10.1103/PhysRevB.90.205213.

URL http://link.aps.org/doi/10.1103/PhysRevB.90.205213

[15] H. R. Lazar, V. Misra, R. S. Johnson, G. Lucovsky, Characteristics of

a metalorganic remote plasma chemical vapor deposited al2o3 gate stacks on

[16] E. Kasper, S. Heim, Challenges of high ge content silicon ger360 sic metaloxidesemiconductor devices, Applied Physics Letters 79 (7) (2001)

973. doi:http://dx.doi.org/10.1063/1.1392973.

URL http://scitation.aip.org/content/aip/journal/apl/79/7/10. $1063 / 1.1392973$ manium structures, Applied Surface Science 224 (1-4) (2004) 3-8. 


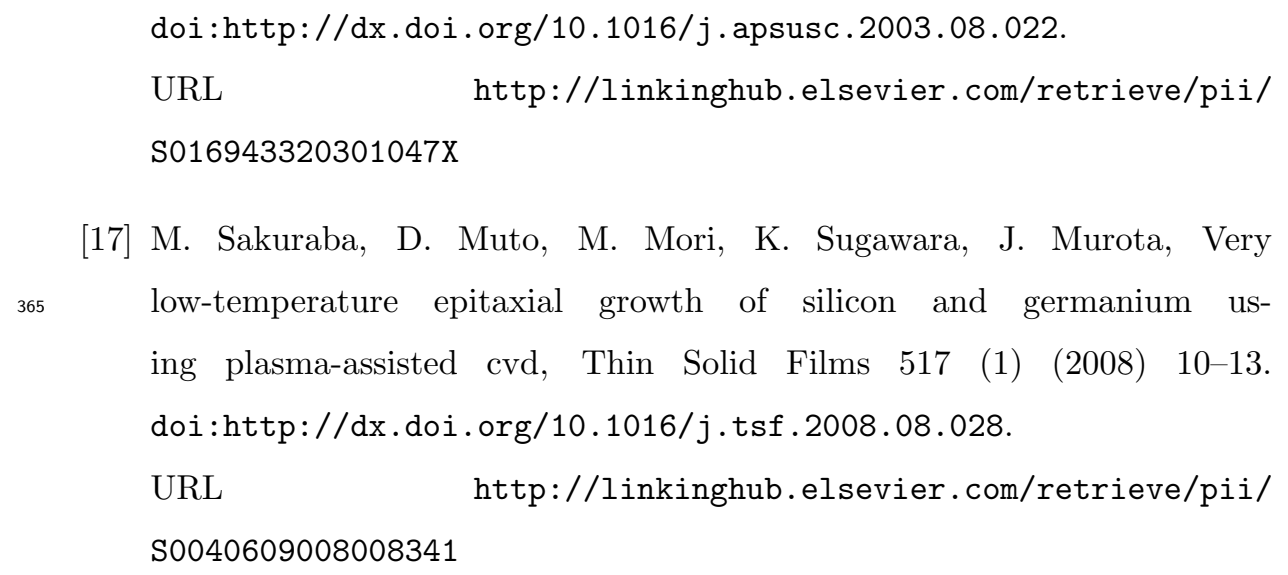

[17] M. Sakuraba, D. Muto, M. Mori, K. Sugawara, J. Murota, Very low-temperature epitaxial growth of silicon and germanium using plasma-assisted cvd, Thin Solid Films 517 (1) (2008) 10-13. doi:http://dx.doi.org/10.1016/j.tsf.2008.08.028 URL http://linkinghub.elsevier.com/retrieve/pii/ S0040609008008341

[18] R. Ito, M. Sakuraba, J. Murota, Hole tunnelling properties in 0 resonant tunnelling diodes with si/strained si0.8ge0.2 heterostructures grown on $\mathrm{si}(100)$ by low-temperature ultraclean lpcvd, Semiconductor Science and Technology 22 (1) (2007) S38-S41. doi:http://dx.doi.org/10.1088/0268-1242/22/1/S09

375 a URL http://stacks.iop.org/0268-1242/22/i=1/a=S09?key= crossref.0d2afee8703ff1338bcd6c2a5f4b8cd2

[19] M. Yoshimoto, R. Yamauchi, D. Shiojiri, G. Tan, S. Kaneko, A. Mata suda, Room-temperature synthesis of epitaxial oxide thin films for a development of unequilibrium structure and novel electronic functionalization Journal of the Ceramic Society of Japan 121 (1409) (2013) 1-9. doi:http://dx.doi.org/10.2109/jcersj2.121.1

1 URL http://japanlinkcenter.org/DN/JST.JSTAGE/jcersj2/121.1? lang=en\&from=CrossRef\&type=abstract

[20] T. Luong, A.Ghrib, M. Dau, M. Zrir, M. Stoffel, V. L. Thanh, R. Daineche, T. Le, V.Heresanu, O. Abbes, M.Petit, M. E. Kurdi, P. Boucaud, H. R. J.Murota, Molecular-beam epitaxial growth of tensile-strained and n-doped ge/si(001) films using a gap decomposition source, Thin Solid Films 557 (2014) 70-75. doi:http://dx.doi.org/10.1016/j.tsf.2013.11.027.

[21] C. Zeng, W. Zhu, S. C. Erwin, Z. Zhang, H. H. Weitering, Initial stages of 
mn adsorption on ge(111), Physical Review B 70 (205340) (2004) 205340.

doi:http://dx.doi.org/10.1103/PhysRevB.70.205340,

URL http://link.aps.org/doi/10.1103/PhysRevB.70.205340

[22] A. Nikiforov, B. Kanter, O. Pchelyakov, Rheed investigation of lim-

घ iting thickness epitaxy during low-temperature si-mbe on (100)

395 surface, Thin Solid Films 336 (1-2) (1998) 179-182. doi:http:

//dx.doi.org/10.1016/S0040-6090(98)01234-6.

1 URL http://linkinghub.elsevier.com/retrieve/pii/ S0040609098012346

[23] A. Spiesser, F. Virot, L.-A. Michez, R. Hayn, S. Bertaina, L. Favre, M. Petit, V. Le Thanh, Magnetic anisotropy in epitaxial mn5ge3 films, Physical Review B 86 (3) (2012) 035211. doi:http://dx.doi.org/10.1103/ PhysRevB.86.035211 URL http://link .aps .org/doi/10.1103/PhysRevB.86.035211

[24] M. Hansen, Constitution of binary alloys, Metallurgy and Metallurgical Engineering Series, McGraw-Hill Book Company, Inc., 1958.

[25] O. Abbes, A. Portavoce, V. Le Thanh, C. Girardeaux, L. Michez, Phase

1 formation during $\mathrm{mn}$ thin film reaction with ge: Self-aligned germanide process for spintronics, Applied Physics Letters 103 (17) (2013) 172405. doi:http://dx.doi.org/10.1063/1.4827100.

URL http://scitation.aip.org/content/aip/journal/apl/103/17/ $10.1063 / 1.4827100$

[26] V. Myagkov, V. Zhigalov, a.a. Matsynin, L. Bykova, Y. Mikhlin, G. Bona darenko, G. Patrin, G. Yurkin, Formation of ferromagnetic germanides by solid-state reactions in 20ge/80mn films, Thin Solid Films 552 (2014) 86-91. doi:http://dx.doi.org/10.1016/j.tsf.2013.12.029. URL http://linkinghub.elsevier.com/retrieve/pii/ S0040609013020920 
[27] M. Gajdzik, C. Sürgers, M. T. Kelemen, H. v. Löhneysen, Strongly enhanced curie temperature in carbon-doped mn5ge3 films, Journal of Magnetism and Magnetic Materials 221 (3) (2000) 248-254. doi:http://dx.doi.org/10.1016/S0304-8853(00) 00494-7. URL http://www.sciencedirect.com/science/article/pii/ S0304885300004947

[28] G. Kappel, G. Fischer, A. Jaegle, On the saturation magnetization of 425 mn5ge3, Physics Letters 45 (3) (1973) 267-268. doi:http://dx.doi.org/ 10.1016/0375-9601(73)90199-0.

[29] A. Spiesser, I. Slipukhina, M.-T. Dau, E. Arras, V. Le Thanh, L. Michez, P. Pochet, H. Saito, S. Yuasa, M. Jamet, J. Derrien, Control of magnetic properties of epitaxial mn5ge3cx films induced by carbon doping, Physical Review B 84 (2011) 165203. doi:http://dx.doi.org/10.1103/ PhysRevB.84.165203

URL http://link.aps.org/doi/10.1103/PhysRevB.84.165203

[30] M. Terada, M. Sakata, H. Nosé, Ferromagnetic resonance in thin films of mn5ge3, Journal of the Physical Society of Japan 34 (3) (1973) 619-622. doi:http://dx.doi.org/10.1143/JPSJ.34.619.

URL http://dx.doi .org/10.1143/JPSJ .34.619 